\title{
An Unusual Case of Haematemesis Due to Herbicidal Poisoning
}

\author{
Vidyashree S. Hulkoti ${ }^{1}$, Sourya Acharya ${ }^{2}$, Amol Andhale ${ }^{3}$, Samarth Shukla ${ }^{4}$ \\ 1,2,3 Department of Medicine, Datta Meghe Institute of Medical Sciences (Deemed to Be University), Sawangi (Meghe), \\ Wardha, Maharashtra, India. ${ }^{4}$ Department of Pathology, Datta Meghe Institute of Medical Sciences \\ (Deemed to Be University), Sawangi (Meghe), Wardha, Maharashtra, India.
}

\section{INTRODUCTION}

Large number of poisoning cases are presenting at hospitals in a developing country like India but very few cases are published in the medical literature. Different poison compounds are consumed with the intention of committing suicide which has a varied effect on the human body. ${ }^{1}$ Herbicide poisoning is also common, amongst all. We note a case of a 39-year-old male presenting with haematemesis due to herbicide poisoning group of aryloxyphenoxypropionates.

The herbicides of aryloxyphenoxypropionate are known as fops, which are a subgroup of the inhibitor category of acetyl-CoA. Usually the aryloxyphenoxypropionates are made from three building blocks: a halo aromatic, hydroquinone, and a propionate ester carrying a 2-position leaving group. ${ }^{2}$

Such compound aryloxyphenoxypropionates provide selective grass weed control, thus causing little to no harm to the wide-leaved crops. Once introduced postemergence, they monitor a wide variety of annual and perennial grasses in cool and warm temperate regions but have much less activity once added to the soil before weed emerges. Some of the big fops are used for grass control including fluazifop, quizalofop, and haloxyfop. ${ }^{2}$

\section{PRESENTATION OF CASE}

A 39-years-old male was brought to our hospital with the alleged history of intentional ingestion of approximately $250 \mathrm{~mL}$ of herbicide named AGIL containing aryloxyphenoxypropionates under the influence of alcohol at his home, following the consumption he had multiple episodes of vomiting and 2 episodes of haematemesis, he complained of diffuse abdominal pain, patient was evaluated in the casualty.

On examination - Patient was afebrile, pulse rate-104 / min, blood pressure-90 / $60 \mathrm{mmHg}$, Sp02-98 \%, Glasgow coma scale $15 / 15$, on systemic examination cardiovascular, respiratory and gastrointestinal systems were normal, patient was initially stabilised with intravenous fluid, gastric lavage done in casualty and patient was immediately shifted to medicine Intensive Care Unit for further management. Routine blood investigation, liver function test, renal functional test and prothrombin time were monitored. After few days patient improved symptomatically but continued to complain about the diffuse abdominal pain. Stool with occult blood was sent for investigation and was found positive; hence, upper GI endoscopy was planned, and report was suggestive of corrosive injury (Zargar classification 3 B) with necrosis seen in whole stomach starting just below GE junction up to antrum. (Figure 1) Patient was then referred to a surgeon and feeding jejunostomy procedure was planned.

\begin{abstract}
Corresponding Author: Dr. Vidyashree S. Hulkoti, Resident, Department of Medicine, Datta Meghe Institute of Medical Sciences (Deemed to Be University), Sawangi (Meghe), Wardha, Maharashtra, India.

E-mail: drvidyahulkoti@gmail.com

DOI: $10.14260 / j e m d s / 2020 / 838$

How to Cite This Article:

Hulkoti VS, Acharya S, Andhale A, et al. An unusual case of haematemesis due to herbicidal poisoning. J Evolution Med Dent Sci 2020;9(50):3823-3824, DOI: $10.14260 /$ jemds/2020/838
\end{abstract}

Submission 20-08-2020,

Peer Review 26-10-2020,

Acceptance 03-11-2020,

Published 14-12-2020.

Copyright (c) 2020 Vidyashree S. Hulkoti et al. This is an open access article distributed under Creative Commons Attribution License [Attribution 4.0 International (CC BY 4.0)] 

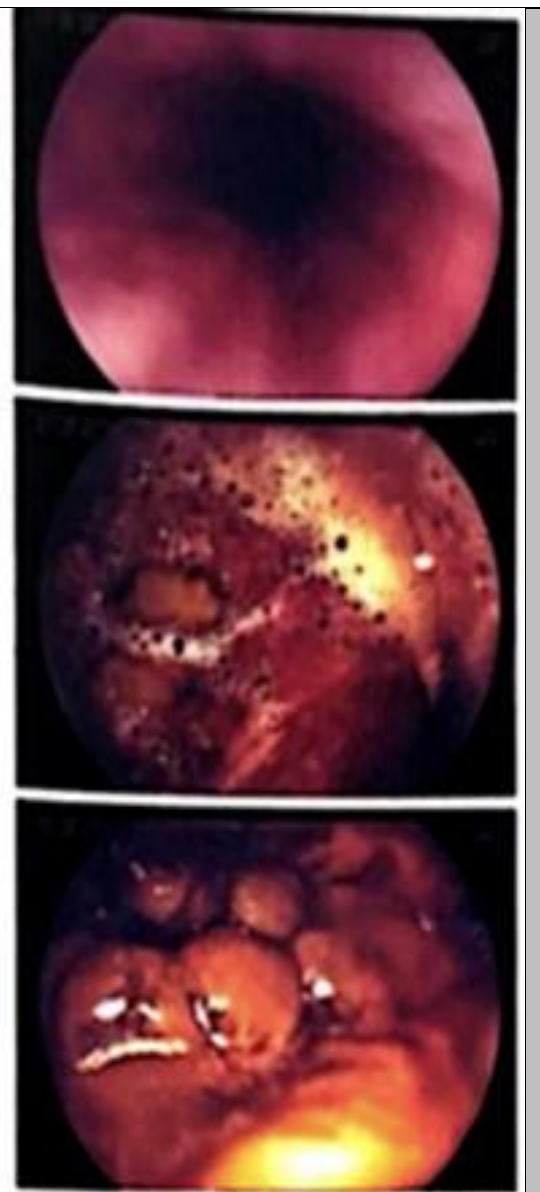

Indication:

Corrosive injury

Sedation:

Local anaesthesia

(lignocaine spray)

Oesophagus:

Normal

LES:

$37 \mathrm{cms}$

Stomach:

Necrosis is seen in

whole stomach

starting just below

GE junction up to

antrum

D1 and D2:

Normal

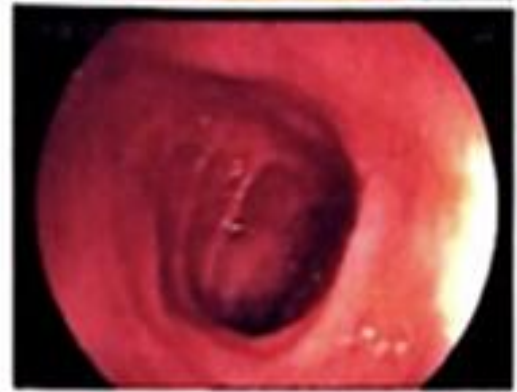

Impression:

Corrosive Injury

(Zargar classification 3B)

Adv:

Feeding Jejunostomy.

Repeat endoscopy

after 1 month

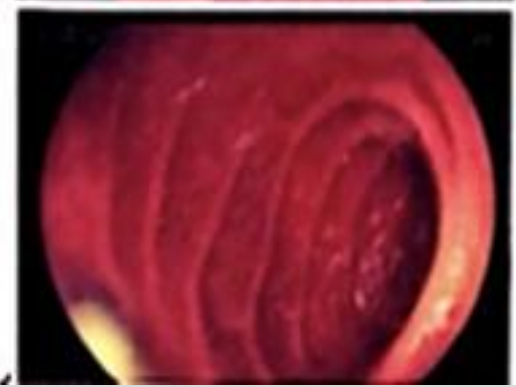

Figure 1. Endoscopic Report of the 39-Year-Old Patient Suggestive of Corrosive Injury and Patient was Advised Feeding Jejunostomy

\section{DISCUSSION}

Consumption of various forms of poisons can affect the body variedly. Toxins may be acidic or alkaline in nature, while corrosive upper GI tract injuries are typically caused by acid ingestion, alkalis are equally responsible. Acid causes corrosive injury via the coagulative necrosis process, while alkali causes liquefaction necrosis and thus alkaline necrosis leads to wider tissue damage. ${ }^{3}$

The toxicity of herbicides consists of different components such as aryloxyphenoxypropionates, glyphosate, paraquet. Aryloxyphenoxypropionates is an aromatic carboxylic acid subfamily that works by inhibiting acetyl coenzyme A carboxylase (AC Case) which is a key enzyme in chloroplast fatty acid biosynthesis. The aryoxyphenoxypropionate's other mode of action is that it depolarizes the membranes, and these depolarised membranes have the greatest resistance to ion motion. ${ }^{1}$

Initially these herbicides work on close meristems in susceptible species, sites where significant cell division and elongation occurs, the primary lethal action of aryloxyphenoxypropionates is meristem inhibition of fatty acid biosynthesis, which ceases plant growth leading to chlorosis and necrosis.

Gastric symptoms such as stomach pain, nausea, and vomiting are commonly reported in human cells. But in this case corrosive effect was noted in the stomach, which could probably have occurred due to carboxylic acid subfamily aryloxyphenoxypropionate.

\section{CONCLUSIONS}

In the above case, herbicide poisoning had led to corrosive injury in the upper GI tract and hence, endoscopy should always be considered in herbicide poisoning patient in the presence of abdominal pain, nausea and vomiting. It is essential to diagnose and treat these corrosive injuries as if left untreated it can lead to complicated stricture formations.

Financial or other competing interests: None.

Disclosure forms provided by the authors are available with the full text of this article at jemds.com.

\section{REFERENCES}

[1] Kalipatnapu S, Reddipogu JS, George SV, et al. Corrosive injuries of the upper gastrointestinal tract: a review of management practices. Current Medical Issues 2018;16(3):92-5.

[2] Zawahir S, Roberts DM, Palangasinghe C, et al. Acute intentional self-poisoning with a herbicide product containing fenoxaprop-P-ethyl, ethoxysulfuron and isoxadifen ethyl: a prospective observational study. Clin Toxicol (Phila) 2009;47(8):792-7.

[3] Ayokanmi 0, Ebenezer TO. Toxic mechanisms of aryloxyphenoxypropionates in target and non-target organisms. Front Environ Sci 2019. 